\title{
(อ) OPEN ACCESS \\ Alcohol and other drugs in suicide in Canada: opportunities to support prevention through enhanced monitoring
}

\author{
Heather Orpana $\odot,{ }^{1,2}$ Norman Giesbrecht, ${ }^{3,4}$ Aliya Hajee, ${ }^{5}$ Mark S Kaplan ${ }^{6}$
}

\begin{abstract}
${ }^{1}$ Centre for Surveillance and Applied Research, Public Health Agency of Canada, Ottawa, Ontario, Canada

${ }^{2} S$ chool of Epidemiology and Public Health, University of Ottawa, Ottawa, Ontario, Canada

${ }^{3}$ Institute for Mental Health Policy Research, Centre for Addiction and Mental Health,

Toronto, Ontario, Canada ${ }^{4}$ Dalla Lana School of Public Health, University of Toronto, Toronto, Ontario, Canada ${ }^{5}$ Downtown West Clinic, Centre for Addiction and Mental Health, Toronto, Ontario, Canada

${ }^{6}$ Luskin School of Public Affairs, University of California, Los Angeles, Los Angeles, California, USA
\end{abstract}

\section{Correspondence to}

Dr Heather Orpana, Centre for Surveillance and Applied Research, Public Health Agency of Canada, Ottawa, ON K1A0K9, Canada; heather. orpana@canada.ca

Received 6 October 2019 Revised 3 February 2020 Accepted 6 February 2020
D Check for updates

(c) Author(s) (or their employer(s)) 2020. Re-use permitted under CC BY-NC. No commercial re-use. See rights and permissions. Published by BMJ.

To cite: Orpana $\mathrm{H}$,

Giesbrecht N, Hajee A, et al.

Inj Prev Epub ahead of print:

[please include Day Month

Year]. doi:10.1136/

injuryprev-2019-043504

\section{ABSTRACT}

The use of alcohol and other drugs has been identified as a significant factor related to suicide through multiple pathways. This paper highlights current understanding of their contributions to suicide in Canada and identifies opportunities for enhancing monitoring and prevention initiatives. Publications from 1998 to 2018 about suicide in Canada and that referred to alcohol or other drugs were identified using PubMed and Google Scholar. A second literature search restricted to articles including results of toxicology testing was conducted by a librarian. We summarised the literature identified on ecological analyses, attributable fractions and deaths, and research including the results of toxicological analyses. Our literature search yielded 5230 publications, and 164 documents were identified for full-text screening. We summarised the findings from 30 articles. Ecological analyses support the association between alcohol sales, annual per capita alcohol consumption and suicide rates. Based on published estimates, approximately a quarter of suicide deaths in Canada are alcohol-attributable, while the estimated attributable fraction for illegal drugs is more variable. Finally, there is a dearth of literature examining the role of acute alcohol and/or drug consumption prior to suicide based on toxicological findings. The proportion of suicide decedents with drugs or alcohol present at the time of death varies widely. While there is evidence on the role of alcohol and drugs in suicide deaths, there is not a large body of research about the acute use of these substances at the time of death among suicide decedents in Canada. Our understanding of the role of alcohol and other drugs in suicide deaths could be enhanced through systematic documentation, which in turn could provide much needed guidance for clinical practice, prevention strategies and policy initiatives.

\section{INTRODUCTION}

Alcohol is a contributing or primary factor in many different chronic diseases, infectious diseases, mental disorders, maternal and child health outcomes, injuries and poisonings, trauma, and social problems. ${ }^{1}$ According to the Global Burden of Disease Study, 2.8 million deaths were attributable to alcohol use in $2016 .^{2}$ Alcohol use was the seventh leading global risk factor for disabilityadjusted life years (DALYs) in 2016, accounting for $1.6 \%$ of total DALYs among women and $6.0 \%$ of total DALYs among men. Among those 15-49 years, alcohol was the leading risk factor, accounting for $2.3 \%$ of total DALYs among women and $8.9 \%$ of total DALYs among men. Similarly, other drugs such as opioids, cannabis and methamphetamine make a significant contribution to overall disease burden. In 2017, drug use accounted for 2.2\% of total all-age DALYs globally, and among those aged 18-49 years it was the fifth leading attributable risk factor, accounting for $4.9 \%$ of total global DALYs. ${ }^{3}$ In Canada, a recent analysis indicated that alcoholrelated costs due to healthcare, law enforcement, workplace disruption and other dimensions totalled \$C14.6 billion in 2014, and were higher than the costs associated with tobacco use. ${ }^{4}$ Drugs including opioids, cannabis, cocaine, other central nervous system (CNS) depressants, other CNS stimulants and other substances (eg, hallucinogens and inhalants) accounted for approximately \$C11.8 billion in costs.

A substantial proportion of alcohol and drugrelated deaths are considered 'violent' deaths, involving various types of trauma, including suicide, and alcohol and other drugs as well as suicide have received attention as topics of international concern. The WHO recognises the harmful use of alcohol and alcohol use disorder as primary risk factors for suicide. ${ }^{5}$ The United Nations Sustainable Development Goals also address suicide as well as alcohol and drug use, through target 3.4 , to reduce premature mortality by one-third by 2030 as measured by indicator 3.4.2, suicide mortality; and target 3.5, to strengthen the prevention and treatment of substance abuse, including the harmful use of alcohol, as measured by indicator 3.5.2, the harmful use of alcohol. ${ }^{6}$ The interrelated nature of suicide and substance use provides an opportunity for countries to address two Sustainable Development Goals simultaneously.

Alcohol and other drugs are associated with death by suicide through a number of pathways. These substances can be a means of suicide, alone or in combination with each other, or in combination with other substances to increase their lethality ${ }^{7}$ as well as to reduce fear and inhibitions prior to attempting suicide. ${ }^{89}$ Alcohol's effects are biphasic, with both stimulant and depressant/sedating effects. ${ }^{10}$ Stimulating effects may be associated with impulsivity, disinhibition or aggression, ${ }^{11}{ }^{12}$ while the sedating effects may lead to feelings of sadness and despair, as well as impaired cognition. ${ }^{10}{ }^{12}$ Both the stimulating and depressant effects of alcohol may mediate suicide-related behaviours. The presence of an alcohol use disorder or a drug use disorder is also associated with a higher risk of 
death by suicide. ${ }^{9}$ Finally, alcohol or drug use may be associated with suicide through a third variable-both alcohol or drug use and alcohol or drug use disorders are often comorbid with other mental illnesses, ${ }^{13}$ and in Western contexts psychological autopsy studies suggest that most suicide decedents were living with some form of mental illness before their deaths. ${ }^{14}$ Ultimately, the relationship between alcohol and other drugs and suicide is multifaceted and complex.

Although there is a clear relationship between alcohol and other drugs and suicide, evidence from Canada has not been summarised in a comprehensive manner. Existing reviews have focused broadly on the relationships between alcohol and suicide $^{15}$ or on a specific facet of alcohol use, such as alcohol use disorder and suicide-related behaviours. ${ }^{16}$ Although these reviews are broadly informative, more specific information is needed to inform the development of surveillance and monitoring systems, and prevention and intervention initiatives in a specific context. For example, research from the USA using the National Violent Death Reporting System (NVDRS) has demonstrated that $37 \%$ of male and $29 \%$ of female suicide decedents had positive blood alcohol (BAC) levels at the time of their death, ${ }^{17}$ with mean levels of BAC exceeding the legal threshold for driving at the time of death. However, given differences between Canada and the USA in terms of alcohol policies and consumption patterns; rates, patterns and means of suicide; and different healthcare systems, these results may not be generalisable. We have not been able to identify any previous reviews summarising the relationship between alcohol and other drugs and suicide in the Canadian context.

The purpose of this paper is to summarise research in Canada on the role of alcohol and other drugs in relation to suicide deaths from ecological studies, studies calculating attributable fractions and from studies including the results of toxicology testing. This will inform enhanced and systematic documentation of these deaths, in addition to providing guidance for clinical practice, prevention strategies and policy initiatives.

\section{METHODS}

We searched for articles through PubMed and Google Scholar using the following keywords: (alcohol or drugs) and (suicide or homicide) and (Canada). We included articles in our narrative review if they were primary research, included homicide or suicide as an outcome, were Canadian studies, published between 1998 and 2018, and (1) provided ecological analyses of the relationship between alcohol or drugs and homicide or suicide, or (2) provided estimates of alcohol or drug-attributable deaths or fractions, or (3) included findings about alcohol or drugs based on toxicology testing. Of 5128 articles initially identified which were screened by title and abstract, 158 were retrieved for fulltext review. Figure 1 visualises the search process. While our original search terms included both suicide and homicide, in this paper we are reporting only on studies that included results related to suicide deaths. Among these 158 articles, 126 were excluded for full-text review. Among the remaining 32 articles, 24 included results related to suicide deaths: 4 articles that presented ecological analyses; 8 articles that presented alcohol or drug-attributable fractions; and 12 studies that presented the results of research including toxicological analysis. A secondary search by a librarian yielded an additional 102 articles. Of these, 6 additional articles were included in the review of studies including information on studies on suicide decedents that included toxicology, for a total of 18 such articles. In total, we included 30 articles in the present review. Figure 1 shows a flow

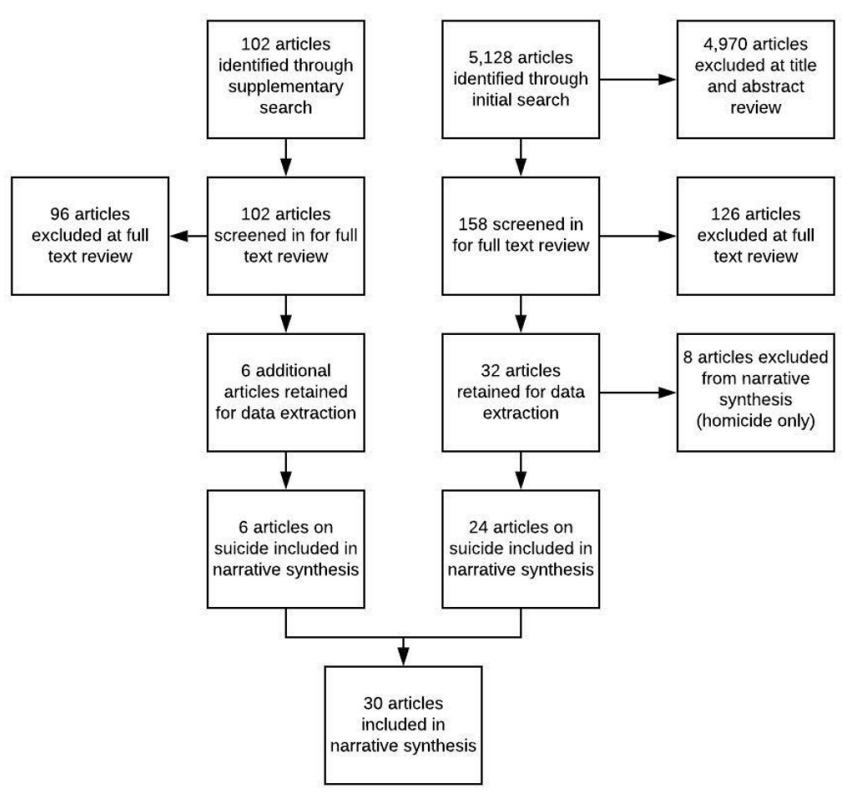

Figure 1 Flow chart of search and screening results.

chart summary of articles identified, screened and included in the study.

\section{RESULTS \\ Ecological studies}

A number of ecological studies have looked at the association between overall alcohol sales and violent deaths at a national or provincial/territorial level. Mann et $a l^{18}$ examined the statistics on alcohol sales and death along with data from surveys on patterns of drinking between 1977 and 1996. They found that per capita alcohol consumption, as well as percentage of daily drinkers, correlated significantly and positively with several types of mortality, including overall rates of suicide. Mann et al's ${ }^{19}$ time series analysis of Manitoba data for 1967-1997 demonstrated a significant relation between per capita consumption measures and suicide mortality rates. Ramstedt ${ }^{20}$ estimated that for every litre increase in alcohol consumption at the population level in Canada, suicide mortality rates increased $4 \%$ overall, and by $3.8 \%$ for men and $6.6 \%$ for women. Stockwell et $a l^{21}$ examined the impact of a rapid rise in the density of private liquor outlets in British Columbia on alcohol-related mortality, and estimated that alcohol-related deaths increased by $3.25 \%$ for each $20 \%$ increase in private liquor store density. They also estimated that 612 suicide deaths were attributable to alcohol use in British Columbia between 2003 and 2008 during the period of increased density of outlets. Overall, ecological studies appear to support a relationship between alcohol sales or other measures of alcohol availability and suicide rates. However, due to limits inherent in ecological analyses, including the ecological fallacy where relationships observed at an aggregate level are incorrectly applied at the individual level, additional studies, such as those employing a natural experiment methodology, are required to confirm these findings. ${ }^{22}$

\section{Alcohol- and drug-attributable suicide and comparative risk assessment}

Our narrative review identified several publications that presented the attributable fraction or attributable deaths due to alcohol and other drugs for suicide (table 1), all of which estimated attributable deaths at a national level. An attributable fraction is defined 
Table 1 Summary of research on alcohol-attributable and drug-attributable deaths and fractions

\begin{tabular}{|c|c|c|c|c|}
\hline \multirow[b]{2}{*}{ Paper } & \multirow{2}{*}{$\begin{array}{l}\text { Reference } \\
\text { year }\end{array}$} & \multirow[b]{2}{*}{ Alcohol/drug consumption data } & \multirow{2}{*}{$\begin{array}{l}\text { Alcohol-attributable } \\
\text { deaths (n)/fraction (\%) }\end{array}$} & \multirow{2}{*}{$\begin{array}{l}\text { Illegal drug-attributable } \\
\text { deaths (n)/fraction (\%) } \\
\text { Suicide }\end{array}$} \\
\hline & & & & \\
\hline Robson et a l $^{24}$ & 1992 & & 918 & \\
\hline Single et $a l^{25}$ & 1992 & $\begin{array}{l}\text { Health Promotion Survey. } \\
\text { Canada's Alcohol and Other Drugs Survey. }\end{array}$ & 918 & 308 \\
\hline Single et $a l^{26}$ & 1995 & $\begin{array}{l}\text { Health Promotion Survey. } \\
\text { Canada's Alcohol and Other Drugs Survey. }\end{array}$ & $\begin{array}{l}955 \\
27 \% \text { men, } 17 \% \text { women }\end{array}$ & $\begin{array}{l}329 \\
14 \% \text { for men, } 3 \% \text { for women }\end{array}$ \\
\hline Popova et $a^{27}$ & 2002 & Provincial coroners' offices. & & $\begin{array}{l}295 \\
5.2 \% \text { for men, } 19.5 \% \text { for women }\end{array}$ \\
\hline Rehm et $a l^{29}$ & 2002 & $\begin{array}{l}\text { Canadian Addictions Survey. } \\
\text { Moderate drinking } \neq .\end{array}$ & 249 premature deaths* & \\
\hline Patra et a $\beta^{30}$ & 2002 & $\begin{array}{l}\text { Canadian Addictions Survey. } \\
\text { High-volume drinkingt. }\end{array}$ & 347 & 90 \\
\hline
\end{tabular}

*Deaths before the age of 70 years.

$t>=40 \mathrm{~g}$ alcohol per day for men, $\geq 20 \mathrm{~g}$ of alcohol per day for women.

$\ddagger<=39 \mathrm{~g}$ of alcohol per day for men, $\leq 19 \mathrm{~g}$ per day for women.

as the percentage of an outcome in the population that would be prevented if the exposure was removed. Attributable deaths are the number of deaths that would be prevented if the exposure was removed ${ }^{23}$ (table 1). In order to calculate alcohol-attributable suicide deaths, Robson et al combined alcohol consumption prevalence with a relative risk (RR) of 1.4 for low-risk drinking and 2.5 for high-risk drinking for suicide. ${ }^{24}$ This results in 918 (788 men, 131 women) alcohol-attributable suicide deaths. ${ }^{24} 25$ A further refinement of these analyses suggested that 955 suicide deaths were alcohol-attributable in $1992 .{ }^{26}$ There were 329 suicide deaths (313 men, 15 women) attributable to illegal drugs (table 1) during this same period. In the original articles, these are titled 'illicit' drugs; however, to be consistent with antistigmatising language, we have changed this to illegal drugs in the text of this paper. Based on a variety of data sources, including coroners' records, Popova et $a l^{27}$ estimated 295 illegal drugattributable suicide deaths. Looking across the full spectrum of alcohol consumption behaviour, Rehm et $a l^{28}$ estimated that 619 suicide deaths were attributable to alcohol in 2001. Rehm et $a l^{29}$ used RR from meta-analysis, alcohol-attributable fraction (AAF) and survey data from the 2003 and 2004 Canadian Addictions Survey (CAS) to estimate the net effects on premature mortality of moderate alcohol consumption among adults in Canada in 2002. Compared with abstainers, they estimated that 249 suicide deaths were attributable to moderate alcohol drinking. Using the same data sources (2003 and 2004 CAS), Patra $e a^{30}$ reported that 347 suicide deaths were attributable to alcohol in 2002. Taylor $e a^{31}$ calculated the AAF for Canada in 2005, modelling a range of drinking scenarios. Among deaths not due to motor vehicle collisions, the largest change in total AAF occurred both for homicide and other intentional injuries at about a 15\% increase in the AAF from the lowest to the highest binge consumption scenarios. Overall, research calculating attributable fractions suggests that about a quarter of suicide deaths are attributable to alcohol in Canada. Estimates for the fraction of suicide deaths attributable to illegal drugs are more variable, ranging from $3 \%$ to almost $20 \%$ in women for suicide and from $5 \%$ to $14 \%$ in men for suicide. ${ }^{2632}$ However, this literature in Canada is relatively dated. Rehm $e t a l^{33}$ reviewed the literature on disease and injuries attributable wholly or in part to alcohol, including suicide, and suggest that chronic patterns of drinking including long-term heavy alcohol use and alcohol use disorder are important to modelling the impact of alcohol on suicide, in addition to acute effects.

\section{Research with toxicology data}

Because drugs, alcohol or other substances can be means of suicide through intentional self-poisoning, many research studies on suicide mention drugs and alcohol in the context of cause of death. While substances can be the direct cause of death, they can also be contributing causes to other causes of suicide death, such as by firearm, suffocation/hanging, drowning, jumping and cutting/piercing. We identified a total of 18 published research studies between 1998 and 2018 that included toxicology findings among suicide decedents in Canada, including studies from most Canadian jurisdictions (all of Canada, Northwest Territories, British Columbia, Alberta, Manitoba, Ontario and Quebec; table 2). Almost all studies focused on a special population or specific cause of death, for example suicide among homicide offenders, railway suicide deaths, drug toxicity suicide deaths, plastic bag suffocation suicide deaths, and deaths among children and youth. Because of the diverse nature of the samples in the reviewed studies, our findings are not generalisable to the population as a whole. Similarly, because of the long period covered, it is possible that changes in approaches to testing and secular trends in suicide and its risk and protective factors may affect results over time.

Among studies that reported toxicology-based alcohol levels, alcohol was identified at the time of death in a significant proportion of decedents. Among 78 suicide decedents in the Northwest Territories between 1982 and 1996, 78\% of decedents were tested for BAC levels. Of these, $43 \%$ tested positive for alcohol and 33\% were at an impaired BAC level of $\geq 0.08 .^{34}$ Drug screening was available for almost half of decedents, and $22 \%$ of these were positive for cannabinoids. In a small study of a cluster of six suicide deaths in Northern Manitoba in 1995, two-thirds of decedents had alcohol or cannabinoids detected 
Table 2 Alcohol and drug toxicology findings among suicide decedents

\begin{tabular}{|c|c|c|c|}
\hline & Period/geography/population & $\begin{array}{l}\text { Suicide } \\
\text { decedents } \\
\text { (n) }\end{array}$ & Toxicology: alcohol or other drugs \\
\hline Isaacs et $\left.a\right|^{34}$ & $\begin{array}{l}\text { 1981-1996 } \\
\text { Northwest Territories }\end{array}$ & 78 & $\begin{array}{l}\text { Alcohol toxicology available for } 78 \% \text { of decedents. } \\
\text { Of these, } 43 \% \text { had positive BAC level at time of death, } 33 \% \text { with an } \\
\text { impaired level. } \\
\text { Drug screens available for } 47 \% \text {, and } 22 \% \text { were positive for } \\
\text { cannabinoids. }\end{array}$ \\
\hline Poulin et $a l^{63}$ & $\begin{array}{l}1993-1995 \\
\text { Halifax deaths investigated by the medical } \\
\text { examiner }\end{array}$ & 20 & $\begin{array}{l}\text { } 42(6.6 \%) \text { deaths were due to drug overdose. } \\
20(47.6 \%) \text { overdose deaths were suicide deaths. } \\
\text { BAC positive in } 20 \text { of } 42(47.6 \%) \text { overdose deaths. }\end{array}$ \\
\hline Wilkie et $a l^{35}$ & $\begin{array}{l}1995 \\
\text { Northern Manitoba suicide cluster }\end{array}$ & 6 & $\begin{array}{l}4(67 \%) \text { decedents had alcohol or cannabinoids detected at time of } \\
\text { death. }\end{array}$ \\
\hline Bourget et $a^{64}$ & $\begin{array}{l}\text { 1991-1998 } \\
\text { Quebec spousal homicide offender suicide deaths }\end{array}$ & 58 & $\begin{array}{l}5.2 \% \text { of offenders who killed their spouse and subsequently died by } \\
\text { suicide were intoxicated at the time. }\end{array}$ \\
\hline Bullock and Diniz $^{7}$ & $\begin{array}{l}\text { 1993-1997 } \\
\text { Ontario plastic bag suffocation suicide deaths }\end{array}$ & 110 & $\begin{array}{l}68 \text { decedents screened for alcohol and drugs, } 9 \text { for alcohol only. } \\
\text { of the } 77 \text { screened for alcohol, } 27(35 \%) \text { were positive, } 11(14 \%)>100 \\
\text { mg\%. } \\
39(57 \%) \text { decedents screened positive for drugs above a therapeutic } \\
\text { level. }\end{array}$ \\
\hline Mitic and Greschner ${ }^{36}$ & $\begin{array}{l}\text { 1996-2000 } \\
\text { British Columbia children and youth suicide deaths }\end{array}$ & 34 & $\begin{array}{l}\text { Alcohol present at time of death in } 32 \% \text { of deaths. } \\
\text { Alcohol mentioned in fatality report in } 71 \% \text { of deaths. }\end{array}$ \\
\hline Langman et $a P^{51}$ & $\begin{array}{l}2000-2003 \\
\text { British Columbia quetiapine poisoning suicide } \\
\text { deaths }\end{array}$ & 3 & $\begin{array}{l}1 \text { case due to mixed drug overdose, including codeine and morphine. } \\
\text { No alcohol reported among } 3 \text { deaths. }\end{array}$ \\
\hline Shaw et $a l^{37}$ & $\begin{array}{l}\text { 1993-2002 } \\
\text { Hamilton youth suicide deaths }\end{array}$ & 31 & $\begin{array}{l}\text { Toxicology available for } 23 \text { deaths. } \\
\text { Alcohol or drugs detected in } 9(29 \%) \text { of deaths. }\end{array}$ \\
\hline Bourget and Gagné ${ }^{65}$ & $\begin{array}{l}\text { 1991-2001 } \\
\text { Quebec paternal filicide offender suicide deaths }\end{array}$ & 26 & $\begin{array}{l}\text { Only } 3(5 \%) \text { offenders used drugs or alcohol at time of filicide, unclear } \\
\text { if this was among those who died by suicide. } \\
\text { Not clear if this is based on toxicology. }\end{array}$ \\
\hline Albion et $\left.a\right|^{52}$ & $\begin{array}{l}2004 \\
\text { Ontario methadone toxicity deaths }\end{array}$ & 3 & $\begin{array}{l}\text { Evidence of suicidal intent in } 3 \text { out of } 45 \text { deaths reviewed. } \\
2(67 \%) \text { suicide deaths were due to illegal methadone. } \\
1(33 \%) \text { case also had positive BAC. }\end{array}$ \\
\hline Sinyor et a $\beta^{38}$ & $\begin{array}{l}\text { 1998-2007 } \\
\text { Toronto poisoning suicide deaths }\end{array}$ & 397 & $\begin{array}{l}\text { Substances causing death: alcohol in } 10 \% \text { of deaths; opioid analgesics } \\
\text { in } 28 \% \text {; sedative/hypnotic/anxiolytic in } 26 \% \text {; tricyclic antidepressants } \\
\text { in } 20 \% \text {. } \\
\text { Non-lethal substances detected in } 55 \% \text { of deaths. }\end{array}$ \\
\hline Madadi et a $\left.\right|^{40}$ & $\begin{array}{l}2006-2008 \\
\text { Ontario suicide and accidental poisoning deaths }\end{array}$ & 585 & $\begin{array}{l}214 \text { opioid-involved suicide poisoning deaths and } 371 \text { suicide } \\
\text { poisoning deaths not involving opioids. } \\
\text { Codeine was present in a higher proportion of opioid-related suicide } \\
\text { deaths vs accidental opioid-related deaths. }\end{array}$ \\
\hline Sinyor et a $/^{66}$ & $\begin{array}{l}2003-2009 \\
\text { Toronto suicide deaths with a holograph* or will }\end{array}$ & 1565 & $\begin{array}{l}15 \text { of } 59 \text { deaths by suicide with holograph or will content had } \\
\text { toxicology performed. } \\
\text { Alcohol present in } 9 \text { deaths, opioids in } 8 \text {, sedative-hypnotic in } 8 \text {, and } \\
\text { other recreational in fewer than } 5,10 \text { multiple drugs present. }\end{array}$ \\
\hline Mishara and Bardon ${ }^{39}$ & $\begin{array}{l}\text { 1999-2008 } \\
\text { Canada railway suicide deaths }\end{array}$ & 428 & $\begin{array}{l}100 \% \text { of deaths had blood toxicology available. } \\
45.8 \% \text { of those who died by suicide had alcohol or drugs in their } \\
\text { blood. }\end{array}$ \\
\hline Gomes et a $\left.\right|^{41}$ & $\begin{array}{l}\text { 1993-2013 } \\
\text { Ontario opioid-related deaths }\end{array}$ & 1197 & $\begin{array}{l}16 \% \text { of suicide poisoning deaths by opioids were alcohol-involved, } \\
\text { similar to the proportion of accidental poisoning deaths by opioids tha } \\
\text { were alcohol-involved (18\%). }\end{array}$ \\
\hline Schaffer et a ${ }^{49}$ & $\begin{array}{l}\text { 1998-2012 } \\
\text { Ontario suicide deaths among people with and } \\
\text { without bipolar disorder }\end{array}$ & 3319 & $\begin{array}{l}\text { Toxicology available for } 93 \% \text { of BD group and } 85 \% \text { of the non-BD } \\
\text { group. } \\
\text { drug present. } \\
\text { d } \\
\text { presen ho non-BD group had positive BAC, } 11 \% \text { had an illegal drug } \\
\text { present. } \\
\text { Between } 5 \% \text { and } 10 \% \text { had lethal levels of alcohol present. }\end{array}$ \\
\hline Solbeck et $a l^{53}$ & $\begin{array}{l}2012-2015 \\
\text { Ontario phenobarbital self-poisoning suicide } \\
\text { deaths }\end{array}$ & 20 & $\begin{array}{l}\text { Among those who died of phenobarbital overdose, } 3 \text { had positive BAC } \\
\text { without evidence of neoformationt. }\end{array}$ \\
\hline Hawkins et $\left.a\right|^{50}$ & $\begin{array}{l}\text { 1998-2012 } \\
\text { Ontario self-poisoning suicide deaths }\end{array}$ & 3616 & $\begin{array}{l}33 \% \text { of those with CVD who died by self-poisoning had alcohol } \\
\text { present, compared with } 46 \% \text { of non-CVD self-poisoning suicide } \\
\text { decedents. }\end{array}$ \\
\hline
\end{tabular}

*Holographs are wills that are entirely handwritten by the testator.

†Neoformation is the generation of alcohol that is the result of bacterial postmortem decomposition.

BAC, blood alcohol; BP, bipolar disorder; CVD, cardiovascular disease. 
at the time of death. ${ }^{35}$ In British Columbia, alcohol was present at the time of death in one-third of 34 children and youth who died by suicide between 1996 and $2000 .{ }^{36}$ Similarly, Shaw et al ${ }^{37}$ found that among 31 youth suicide deaths in Hamilton between 1993 and 2002, toxicology was conducted on 23 decedents, and alcohol or drugs were detected in $29 \%$ of these.

Sinyor $e t a l^{38}$ report that among 397 people who died by intentional self-poisoning suicide in Toronto, alcohol was found in lethal amounts in 10\% of decedents. Opioids were present in lethal amounts in $28 \%$ of deaths, sedative hypnotic or anxiolytics in $26 \%$ and tricyclic antidepressants in $20 \%$. While death in half of intentional self-poisoning suicide deaths was caused by only one substance, non-lethal substances were detected in 55\% of deaths. According to Mishara and Bardon, ${ }^{39}$ almost half of 428 people who died from railway suicide in Canada between 1999 and 2008 had drugs or alcohol detected in their blood on toxicology screening. Among 110 people who died from plastic bag suffocation suicide in Ontario between 1993 and 1997, 68 decedents were screened for alcohol and drugs and 9 were screened for alcohol only. ${ }^{7}$ Thirty-five per cent screened positive for alcohol, with $14 \%$ above $100 \mathrm{mg} \%$. Of those screened for drugs, $57 \%$ were positive for drugs above therapeutic levels.

A number of studies have focused on opioids and suicide by intentional self-poisoning. From 2006 to 2008, there were 214 suicide deaths by opioid poisoning in Ontario and 371 intentional self-poisoning suicide deaths not involving opioids. Codeine was present in a higher proportion of intentional self-poisoning suicide deaths than accidental opioid poisoning deaths. ${ }^{40}$ Gomes et $a l^{41}$ report that between 1993 and 2013, approximately $20 \%$ of intentional self-poisoning by opioids deaths in Ontario involved alcohol which is slightly lower than the proportion of alcohol-involved accidental poisoning by opioids deaths (26\%).

\section{DISCUSSION}

In summary, alcohol and other drugs are present at the time of death in an important, but variable, proportion of suicide decedents, beyond those who die by intentional self-poisoning. However, based on the literature reviewed for Canada from 1998 to 2018 , this proportion varies by subpopulation and over time. More comprehensive data on alcohol and drugs present at the time of death by suicide would provide valuable information for prevention activities, and those summarising research on alcohol-involved and drug-involved suicide deaths should be aware of the variability in coverage of toxicology testing. Death investigations in Canada fall under provincial or territorial jurisdiction. As such, there is variability in the legislation, practices and procedures that guide and are used to investigate unexplained, sudden or violent deaths, including those that may be by suicide. ${ }^{42}$ These differences, such as variable autopsy rates, may result in differences in observed patterns of the association between alcohol, other drugs and suicide between jurisdictions. An analysis of all coroner records for suicide deaths in Montreal in 2007-2009 also identified missing information as a significant challenge to using these records for research to inform public health and prevention. ${ }^{43}$ These challenges are not unique to Canada; open cases, missing information and inconsistent practices have been identified as important limitations of data from coroner and medical examiner data in Australia and the USA. ${ }^{44} 45$ Future research should carefully document coroner and medical examiner practices in order to account for these regional variations during analysis.

The published research that we identified provides some insights into alcohol and other drugs as contributing factors to suicide deaths in Canada. However, there is a dearth of literature in the Canadian context, with an average of less than 10 papers per year published between 1998 and 2018.

The ecological studies that we located tended to focus on alcohol, with a general finding that higher levels of alcohol sales or consumption were associated with higher suicide rates, a general finding not out of line with research in the USA ${ }^{46}$ and Europe. ${ }^{47}$ Studies calculating attributable fractions also focused on alcohol, with a small number of studies also including illegal drugs. $^{2627}$ These studies estimate that about a quarter of suicide deaths are attributable to alcohol, ${ }^{26} 31$ although Rehm et $a l^{28}$ suggested lower AAF at $18 \%$ for men and 14\% for women for suicide. The attributable fraction for illegal drugs is even more variable. ${ }^{2627}$ With approximately 4000 suicide deaths per year in Canada, ${ }^{48}$ this means that about 1000 suicide deaths are attributable to alcohol. Future research should take a more nuanced approach to comparative risk assessment, considering daily alcohol consumption, patterns, such as heavy episodic drinking, and alcohol use disorder. ${ }^{33}$

However, studies using ecological designs or presenting attributable fractions do not provide information on the characteristics of the decedents, their life experiences, drinking or drug use patterns, or methods of suicide. We identified a small number of studies on suicide that included toxicology data and provided some information on these dimensions (table 2). A number of these studies were conducted in Ontario or Quebec, or on special populations including among children and youth, ${ }^{36} 37$ people with a specific mental disorder or chronic disease, ${ }^{49} 50$ or those who died by a specific means of suicide. ${ }^{73-4151-53}$ The higher proportion of studies from Ontario and Quebec may be due to special institutional support, arrangements that encourage attention to suicide deaths, or the interest of researchers in the jurisdiction. For research on special populations, these foci are likely due to a well-founded perception that violent death (especially suicide) is more common in some populations than in others in Canada. Nonetheless, alcohol consistently appears present at the time of death among a significant proportion of suicide decedents.

Without seeking to detract from the intent or findings of the studies highlighted in tables 1 and 2, we cannot confidently conclude that they provide representative estimates of the relationship between acute alcohol or drug use among suicide decedents. This makes it difficult to summarise the association of acute alcohol or drug use with suicide, which is necessary to provide a fulsome picture of alcohol-related and drug-related harms. A specific study may be representative of deaths with a narrow focus, or region, but not beyond that. In short, ecological research can represent a province, territory or country, but typically does not provide details on the characteristics of the decedents. While specific studies may provide those details along with results of toxicology testing, these may not be representative of a jurisdiction.

Few studies that make use of toxicological findings make policy recommendations. This may be because these tend to be smaller studies, sometimes conducted by psychiatrists with a focus on individual characteristics with a goal to inform clinical care. In contrast, the ecological studies and papers on attributable fractions tended to be conducted by policy or public health researchers, and were more likely to make policy suggestions with a goal of minimising or mitigating the harmful contribution of alcohol and drugs to suicide. ${ }^{21}$ Research based on NVDRS in the USA has been positioned to inform suicide prevention at multiple levels, particularly from a policy perspective. ${ }^{5455}$ Analyses of the NVDRS data combined with data on off-premise and 
on-premise alcohol outlet density demonstrated that higher offpremise alcohol outlet density is associated with a greater share of alcohol-involved suicide for men. Another example using the NVDRS data, combined with economic data, showed that after the onset of the recession in 2008, suicide deaths with alcohol intoxication increased by $7 \% .^{56}$ Studies such as these provide evidence that can underscore the importance of alcohol harm reduction, including the use of policies to reduce access and availability, as part of suicide prevention strategies, particularly during economic downturns.

In summary, a consistent and comprehensive system of documenting violent deaths, including suicide, in Canada will contribute to better understanding the causes and correlates of suicide; identifying high-risk populations for targeted/selective interventions; informing treatment, health and social care; and providing guidance to those who plan, implement and assess the impact of alcohol or other drug policies designed to prevent and reduce suicide deaths. In the future, studies on the role of alcohol and drugs in suicide in Canada would inform contextually relevant public health programmes aimed at reducing the harmful use of alcohol and treating alcohol use disorder, important components of comprehensive suicide prevention programmes as described by the WHO. ${ }^{5}$ Because acute use of alcohol and alcohol use disorder are correlated but distinct risk factors for suicidal behaviour, it is essential that researchers develop and test clinically oriented interventions complemented with primary prevention strategies to lower the prevalence of alcohol involvement in suicidal behaviour. ${ }^{57}$ Such studies would account for the unique profile of Canada with respect to the sociodemographic characteristics of the population, alcohol policies, population consumption patterns and patterns of suicide.

Our initiative had several limitations. We did not conduct a systematic review, and some papers may not have been identified with our search strategy. However, a supplementary search was conducted by a librarian and only six relevant, previously unidentified papers were added. We were limited by what the authors of the original research papers focused and reported on. Some papers did not include full information that would allow us to understand the proportion of decedents that had toxicology screenings, which substances were screened for, and what proportion of decedents screened positive for alcohol and/ or other drugs.

There are also strengths. To our knowledge this is the first overview of alcohol and drugs and suicide deaths in Canada that incorporates findings from ecological studies, studies calculating alcohol-attributable and drug-attributable fractions and deaths, and research using toxicological data. It is timely, in light of the recently reported costs from alcohol-related and drug-related harms ${ }^{4}$ and high rate of opioid and other drug-related deaths in Canada. ${ }^{58}$ While the rate of opioid and other drug poisoning deaths in Canada has been rising, it appears that this increase is due predominately to an increase in accidental drug poisoning deaths (primarily due to opioids), and not to an increase in intentional opioid-related drug self-poisoning deaths. ${ }^{5960}$ In the USA, there has been a modest increase in the rate of intentional selfpoisoning by opioids suicide deaths between 2000 and 2017, from 0.27 to 0.58 per $100000 .{ }^{61}$ The existing Canadian literature provides more information on longer-term or chronic alcohol use associated with suicide than acute use of alcohol associated with suicide, although studies from the USA have highlighted the high proportion of suicide deaths involving acute alcohol use, particularly those using more violent means such as firearms. ${ }^{62}$ While it is beyond the scope of this preliminary work, future initiatives should examine how suicide is systematically documented in several other countries and what toxicology data are collected and which drugs are assessed.

Acknowledgements Thank you to XiaoHong Jiang for assisting with article retrieval, and the Public Health Agency of Canada library for conducting a literature search.

Contributors NG conceived the study. AH identified and screened the articles. NG and $\mathrm{HO}$ synthesised the data. NG, $\mathrm{HO}$ and MSK interpreted the data. NG and HO drafted the manuscript. NG, HO, AH and MSK critically revised the manuscript.

Funding MSK's work on this study was partially supported by a grant from the Fulbright Specialist Program (FSP-P005326).

Competing interests None declared.

Patient and public involvement Patients and/or the public were not involved in the design, or conduct, or reporting, or dissemination plans of this research.

Patient consent for publication Not required.

Provenance and peer review Not commissioned; externally peer reviewed.

Open access This is an open access article distributed in accordance with the Creative Commons Attribution Non Commercial (CC BY-NC 4.0) license, which permits others to distribute, remix, adapt, build upon this work non-commercially, and license their derivative works on different terms, provided the original work is properly cited, appropriate credit is given, any changes made indicated, and the use is non-commercial. See: http://creativecommons.org/licenses/by-nc/4.0/.

\section{ORCID iD}

Heather Orpana http://orcid.org/0000-0001-9982-981X

\section{REFERENCES}

1 World Health Organization. Global status report on alcohol and health. Geneva: World Health Organization, 2011.

2 GBD 2016 Alcohol Collaborators. Alcohol use and burden for 195 countries and territories, 1990-2016: a systematic analysis for the global burden of disease study 2016. Lancet 2018:392:1015-35.

3 Institute of Health Metrics and Evaluation. Global burden of disease compare tool, 2018. Available: https://vizhub.healthdata.org/gbd-compare/ [Accessed 20 Feb 2018].

4 Canadian Substance Use Costs and Harms Scientific Working Group. Canadian substance use costs and harms 2007 to 2014. Ottawa: Canadian Council on Substance Use and Addiction, 2018

5 World Health Organization. Suicide prevention: A global imperative. Geneva: World Health Organization, 2014

6 United Nations. Sustainable development knowledge platform: goal 3, 2019. Available: https://sustainabledevelopment.un.org/sdg3 [Accessed 28 Jan 2020]

7 Bullock MJ, Diniz D. Suffocation using plastic bags: a retrospective study of suicides in Ontario, Canada. J Forensic Sci 2000:45:14736J-13.

8 Bagge $\mathrm{CL}$, Conner KR, Reed L, et al. Alcohol use to facilitate a suicide attempt: an event-based examination. J Stud A/cohol Drugs 2015:76:474-81.

9 Borges G, Loera CR. Alcohol and drug use in suicidal behaviour. Curr Opin Psychiatry 2010:23:195-204.

10 Hendler RA, Ramchandani VA, Gilman J, et al. Stimulant and sedative effects of alcohol. Curr Top Behav Neurosci 2013:13:489-509.

11 Beck A, Heinz A. Alcohol-Related aggression-social and neurobiological factors. Dtsch Arzteb/ Int 2013:110:711-5.

12 Sher L. Alcohol consumption and suicide. QJM - Mon J Assoc Physicians 2006:99:57-61.

13 Currie SR, Patten SB, Williams JVA, et al. Comorbidity of major depression with substance use disorders. Can J Psychiatry 2005;50:660-6.

14 Arsenault-Lapierre G, Kim C, Turecki G. Psychiatric diagnoses in 3275 suicides: a meta-analysis. BMC Psychiatry 2004;4.

15 Pompili M, Serafini G, Innamorati M, et al. Suicidal behavior and alcohol abuse. Int J Environ Res Public Health 2010;7:1392-431.

16 Darvishi N, Farhadi M, Haghtalab T, et al. Alcohol-Related risk of suicidal ideation, suicide attempt, and completed suicide: a meta-analysis. PLoS One 2015; 10:e0126870.

17 Kaplan MS, McFarland BH, Huguet N, et al. Acute alcohol intoxication and suicide: a gender-stratified analysis of the National violent death reporting system. Inj Prev 2013;19:38-43.

18 Mann RE, Suurvali HM, Smart RG. The relationship between alcohol use and mortality rates from injuries: a comparison of measures. Am J Drug Alcohol Abuse 2001:27:737-47.

19 Mann RE, Zalcman RF, Rush BR, et al. Alcohol factors in suicide mortality rates in Manitoba. Can J Psychiatry 2008;53:243-51

20 Ramstedt M. Alcohol and suicide at the population level--the Canadian experience. Drug Alcohol Rev 2005;24:203-8. 
21 Stockwell T, Zhao J, Macdonald S, et al. Impact on alcohol-related mortality of a rapid rise in the density of private liquor outlets in British Columbia: a local area multi-leve analysis. Addiction 2011;106:768-76.

22 Dunning T. Natural experiments in the social sciences : a design-based approach. Cambridge University Press, 2012.

23 Walter SD. The estimation and interpretation of attributable risk in health research. Biometrics 1976;32:829.

24 Robson LS, Single E, Xie X, et al. The cost of alcohol-attributable injuries and poisonings in Canada, 1992. Contemp Drug Prob/ 1998;25:421-39.

25 Single E, Robson L, Rehm J, et al. Morbidity and mortality attributable to alcohol, tobacco, and illicit drug use in Canada. Am J Public Health 1999;89:385-90.

26 Single E, Rehm J, Robson L, et al. The relative risks and etiologic fractions of different causes of death and disease attributable to alcohol, tobacco and illicit drug use in Canada. CMAJ 2000;162:1669-75.

27 Popova S, Rehm J, Patra J. Illegal drug-attributable mortality and potential years of life lost. Contemp Drug Prob/ 2006;33:343-66.

28 Rehm J, Patra J, Popova S. Alcohol-attributable mortality and potential years of life lost in Canada 2001: implications for prevention and policy. Addiction 2006:101:373-84.

29 Rehm J, Patra J, Taylor B. Harm, benefits, and net effects on mortality of moderate drinking of alcohol among adults in Canada in 2002. Ann Epidemiol 2007; 17:S81-6.

30 Patra J, Taylor B, Rehm J. Deaths associated with high-volume drinking of alcohol among adults in Canada in 2002: a need for primary care intervention? Contemp Drug Prob/ 2009;36:283-301.

31 Taylor BJ, Shield KD, Rehm JT. Combining best evidence: a novel method to calculate the alcohol-attributable fraction and its variance for injury mortality. BMC Public Health 2011;11:265.

32 Popova S, Rehm J, Patra J, et al. Illegal drug-attributable morbidity in Canada 2002. Drug Alcohol Rev 2007;26:251-63.

33 Rehm J, Baliunas D, Borges GLG, et al. The relation between different dimensions of alcohol consumption and burden of disease: an overview. Addiction 2010;105:817-43.

34 Isaacs S, Keogh S, Menard C, et al. Suicide in the northwest territories: a descriptive review. Chronic Dis Can 1998:19:152-6.

35 Wilkie C, Macdonald S, Hildahl K. Community case study: suicide cluster in a small Manitoba community. Can J Psychiatry 1998;43:823-8.

36 Mitic W, Greschner J. Alcohol's role in the deaths of bc children and youth. Can J Public Health 2002;93:173-5.

37 Shaw D, Fernandes JR, Rao C. Suicide in children and adolescents: a 10-year retrospective review. Am J Forensic Med Pathol 2005;26:309-15.

38 Sinyor M, Howlett A, Cheung AH, et al. Substances used in completed suicide by overdose in Toronto: an observational study of coroner's data. The Canadian Journal of Psychiatry 2012;57:184-91.

39 Mishara BL, Bardon C. Characteristics of Railway suicides in Canada and comparison with accidental Railway fatalities: implications for prevention. Saf Sci 2017;91:251-9.

40 Madadi P, Hildebrandt D, Lauwers AE, et al. Characteristics of opioid-users whose death was related to opioid-toxicity: a population-based study in Ontario, Canada. PLoS One 2013;8:e60600-6.

41 Gomes T, Juurlink DN, Mamdani MM, et al. Prevalence and characteristics of opioid-related deaths involving alcohol in Ontario, Canada. Drug Alcohol Depend 2017;179:416-23.

42 Kelsall D, Bowes MJ. No standards: medicolegal investigation of deaths. CMAJ 2016;188:169.

43 Houle J, Guillou-Ouellette C. Coroners' records on suicide mortality in Montréal: limitations and implications in suicide prevention strategies. Chronic Dis Inj Can 2014;34:23-9.
44 Bugeja L, Ibrahim JE, Ferrah N, et al. The utility of medico-legal databases for public health research: a systematic review of peer-reviewed publications using the National coronial information system. Health Res Policy Syst 2016;14:28.

45 Warner M, Paulozzi LJ, Nolte KB, et al. State variation in certifying manner of death and drugs involved in drug intoxication deaths. Academic Forensic Pathology 2013;3:231-7

46 Gruenewald PJ, Ponicki WR, Mitchell PR. Suicide rates and alcohol consumption in the United States, 1970-89. Addiction 1995:90:1063-75.

47 Norström T, Rossow I. Alcohol consumption as a risk factor for suicidal behavior: a systematic review of associations at the individual and at the population level. Arch Suicide Res 2016:20:489-506.

48 Statistics Canada. Table 13-10-0156-01 deaths by cause, chapter XX: external causes of morbidity and mortality (V01 to Y89), 2019. Available: https://www150.statcan.gc. ca/t1/tbl1/en/tv.action?pid=1310015601 [Accessed 15 Apr 2019].

49 Schaffer A, Weinstock LM, Sinyor M, et al. Self-Poisoning suicide deaths in people with bipolar disorder: characterizing a subgroup and identifying treatment patterns. Int J Bipolar Disord 2017:5:16

50 Hawkins M, Schaffer A, Sinyor M, et al. Suicide deaths by intentional self-poisoning in people with cardiovascular disease. Gen Hosp Psychiatry 2018:52:41-7.

51 Langman LJ, Kaliciak HA, Carlyle S. Fatal overdoses associated with quetiapine. J Anal Toxicol 2004;28:520-5.

52 Albion C, Shkrum M, Cairns J. Contributing factors to methadone-related deaths in Ontario. Am J Forensic Med Pathol 2010;31:313-9.

53 Solbeck P, Snowdon V, Rajagopalan A, et al. Suicide by fatal pentobarbital intoxication in Ontario, Canada, from 2012 to 2015. J Forensic Sci 2019;64:309-13.

54 Kaplan MS, Caetano R, Giesbrecht N, et al. The National violent death reporting system: use of the restricted access database and recommendations for the system's improvement. Am J Prev Med 2017:53:130-3.

55 Giesbrecht N, Huguet N, Ogden L, et al. Acute alcohol use among suicide decedents in 14 us states: impacts of off-premise and on-premise alcohol outlet density. Addiction 2015;110:300-7.

56 Kaplan MS, Huguet N, Caetano R, et al. Economic contraction, alcohol intoxication and suicide: analysis of the National violent death reporting system. Inj Prev 2015;21:35-41.

57 Conner KR, Bagge CL, Goldston DB, et al. Alcohol and suicidal behavior: what is known and what can be done. Am J Prev Med 2014;47:S204-8.

58 Strang R. Commentary - Broadening our understanding of Canada's epidemics of pharmaceutical and contaminated street drug opioid-related overdoses. Health Promot Chronic Dis Prev Can 2018:38:309-10.

59 Chan EYL, McDonald BM, Brooks-Lim E, et al. At-a-glance - The role of opioid toxicity in suicide deaths in Alberta, 2000 to 2016. Health Promot Chronic Dis Prev Can 2018:38:343-7.

60 Public Health Agency of Canada. National report: apparent Opioid-related deaths in Canada, 2019. Available: https://infobase.phac-aspc.gc.ca/datalab/nationalsurveillance-opioid-mortality.html\#AORD [Accessed 4 May 2019]

61 Olfson M, Rossen LM, Wall MM, et al. Trends in intentional and unintentional opioid overdose deaths in the United States, 2000-2017. JAMA 2019;322:2340-2.

62 Kaplan MS, Huquet N, McFarland BH, et al. Use of alcohol before suicide in the United States. Ann Epidemiol 2014;24:588-92.

63 Poulin C, Stein J, Butt J. Surveillance of drug overdose deaths using medical examiner data. Chronic Dis Can 1998;19:177-82.

64 Bourget D, Gagné P, Moamai J. Spousal homicide and suicide in Quebec. J Am Acad Psychiatry Law 2000:28:179-82.

65 Bourget D, Gagné P. Paternal filicide in Québec. J Am Acad Psychiatry Law 2005:33:354-60.

66 Sinyor M, Schaffer A, Hull I, et al. Last wills and testaments in a large sample of suicide notes: implications for testamentary capacity. Br J Psychiatry 2015:206:72-6. 